with the PHO-9, and classified as mild or moderate to severe. Ordinal logistic regression was used to assess statistical associations between depression and sex, age, illiteracy, family income and centre.

Results 1020 participants were included, 446 in São Paulo and 574 in Manaus, of whom 248 (24.3\%; 95\% CI 21.7 to 27.1$)$ were classified as mild depression and 93 (9.1\%; $95 \%$ CI 7.4 to 11.1$)$ as moderate to severe depression. The prevalence of mild and moderate to severe depression was very similar in the two centres. Women were almost twice as likely as men to present with depression of any severity. We did not find any association between depression and age, illiteracy or family income.

Conclusion Depression is highly prevalent among primary care clients, especially women. Mental healthcare must be integrated into primary care in order to reduce the treatment gap for depression.

\section{P2-528 ADULT PERCEPTIONS OF YOUTH MENTAL HEALTH ISSUES IN A CANADIAN PROVINCE}

doi:10.1136/jech.2011.142976m.55

${ }^{1}$ A Metcalfe, ${ }^{*}{ }^{1,2} \mathrm{~S}$ Tough, ${ }^{2} \mathrm{~J}$ Salegio, ${ }^{2} \mathrm{~T}$ Hanson. ${ }^{1}$ University of Calgary, Calgary, Alberta, Canada; ${ }^{2}$ Alberta Centre for Child, Family \& Community Research, Edmonton, Alberta, Canada

Although $15 \%$ of Canadian youth experience mental health problems, barriers to disclosure and treatment exist. This population-based study assessed adult's beliefs about the prevalence of mental illness among youth, treatment for mental illness, and comfort interacting with youth with moderate mental health problems. In 2010 a random sample of 1203 adults residing in Alberta Canada were surveyed. $\chi^{2}$ Tests and t-tests were used to understand responses by demographic factors. Logistic regression was used to determine factors predictive of Albertans comfort in interacting with youth with moderate mental health problems. Twenty percent were able to correctly identify the prevalence of youth mental health problems. Over $50 \%$ stated that they believed that $<10 \%$ of youth with mental health problems received treatment. Approximately $70 \%$ of the sample reported they would be comfortable interacting with youth with moderate mental health problems in work, school, social and community settings. Consistent predictors of comfort interacting with youth with moderate mental health problems included: being between the ages of 18-24, high school completion, Caucasian ethnicity, and annual household income $>\$ 40000 /$ year. There are meaningful gaps in Albertans understanding of the prevalence of youth mental health issues, but the majority of adults would be comfortable interacting with youth with moderate mental health problems. Many respondents identified that youth with mental health problems may not be receiving treatment. Increased public awareness about the prevalence and detrimental impact of youth mental health issues may help policy makers allocate resources to effective screening and treatment for youth with mental health concerns.

\section{P2-529 CHILDREN LIVING IN POOR HYGIENE AND SANITATION CONDITIONS: WHY DOES IT MATTER?}

doi:10.1136/jech.2011.142976m.56

'S Nadeem,* ${ }^{2} \mathrm{~B}$ I Avan. 'Aga Khan University-Human Development Programme, Karachi, Pakistan; ${ }^{2}$ Immpact, School of Medicine \& Dentistry, University of Aberdeen, Aberdeen, UK

Background It is estimated that at least 200 million children, mostly from developing countries, suffer from developmental delays. Poor hygiene and sanitation conditions are known to influence growth faltering and increased risk of morbidity and mortality, yet little is know about role of these conditions on child growth and development. The study aims to contribute to an understanding of the relationship between family hygiene, sanitary conditions and psychomotor development in the first 3 years of life.
Method A cross sectional household survey was conducted in urban and rural Sindh, Pakistan, by trained personnel. Children aged $<3$ $(n=1244)$ were assessed at home visits using (1) Bayley's Infant Developmental Scale for psychomotor development; (2) anthropometric status, and (3) socio-economic, hygiene and sanitation conditions via maternal interview. Socioeconomic, hygiene and sanitation indices are created using principal component analyses

Results Rural areas are highly correlated with hygiene index $(\mathrm{HI})$ and sanitation index (SI), as compared to their urban counterparts. Age and sex adjusted SI is highly correlated with socioeconomic index (SEI). Multilevel modelling analysis showed that SI is significantly associated with child's delayed development, stunting and being underweight; while $\mathrm{HI}$ is associated with underweight and stunting status of children, independent of SEI and rural-urban neighbourhood.

Conclusion Due to a strong association between hygiene and sanitation conditions and development, recognition should be given to the growth and developmental needs of children living in such conditions.

\section{P2-530 SOCIODEMOGRAPHIC PROFILE AND EFFICACY OF 4 ART REGIMES IN HIV PATIENTS REGISTERED AT AN ART CENTER-A DEVELOPING NATION SCENARIO}

doi:10.1136/jech.2011.142976m.57

V Nagaraja,* M A Khan, G Bhat. MMC \& Rl, Karnataka, India

Introduction People living with HIV in 2008 worldwide are 33.4 million with 2.7 million new cases and 2 million deaths. Southeast Asia has 4.7 million HIV patients. Five countries account for majority of the HIV infections-India (2.31 million), Thailand, Myanmar, Indonesia and Nepal. Hence we sought to study the sociodemographic profile of HIV patients registered at ART center in Mysore. Cluster Designation 4 (CD4) count at the initiation of ART and 6 months thereafter were compared.

Methods The study sample was taken from the records of the ART center at Krishnarajendra hospital, Mysore that consisted of 1702 patients on ART from June 2007 to March 2010. Socioeconomic $\&$ demographic details, sexual practices, HIV status (WHO staging) \& CD4 counts at the initiation and after 6 months of treatment were collected.

Results Majority of the patients on ART (77\%) were males between 21 and 40 years, educated heterosexuals who mainly presented with fever and weight loss. $68 \%$ of spouses knew their HIV status and among them $36 \%$ were HIV positive. Majority of them were categorised under stage 3 . There was an improvement in mean CD4 count by around 200 . ZDV +LMV +NVP regime showed a significant increase in mean CD4count over the other three regimes and there was statistically significant correlation.

Conclusion Most of the HIV patients were young educated heterosexual males and showed a significant increase in the CD4 cell count after 6 months of antiretroviral therapy.

\section{P2-531 A COMPARATIVE STUDY OF FACTORS AFFECTING PSYCHOLOGICAL WELL-BEING OF URBAN AND RURAL ADOLESCENTS}

doi:10.1136/jech.2011.142976m.58

V Nagaraja, ${ }^{*}$ M A Khan, G Bhat. Mysore Medical College and Research Institute, Mysore, Karnataka, India

Aims and Objectives We have limited studies and data allowing us a bleak tunnel vision into the world of adolescent mental health. A comparative study was initiated to have a better understanding of 